\title{
EL MOVIMIENTO ESTUDIANTIL SECUNDARIO EN LA ARGENTINA DEMOCRÁTICA: UN RECORRIDO POSIBLE POR SUS CONTINUIDADES Y RECONFIGURACIONES. PROVINCIA DE BUENOS AIRES, 1983-2013
}

\begin{abstract}
MARINA LARRONDO*
RESUMEN

Este trabajo se propone mostrar el recorrido seguido por el movimiento estudiantil secundario (MES en adelante) en Argentina ${ }^{1}$ durante treinta años de democracia. Planteamos como hipótesis interpretativa que los cambios en su conformación y actuación han estado atravesados por las articulaciones y desarticulaciones de las identidades políticas más amplias en el marco de la puesta en vigor y crisis del proyecto económico neoliberal. El análisis evidencia cómo y por qué esta forma de participación política juvenil ha oscilado entre el rechazo y la resignificación de la política institucional/partidaria; como así también las implicancias de ello en sus marcos de acción colectiva y demandas.
\end{abstract} PALABRAS CLAVE: POLÍTICA Y JUVENTUDES, ESCUELA SECUNDARIA,
ORGANIZACIONES ESTUDIANTILES

* Doctora en Ciencias Sociales por la Universidad Nacional de General Sarmiento/IDES. Magíster en Educación (Universidad de San Andrés) y Licenciada en Sociología (Universidad de Buenos Aires). Becaria Postdoctoral del Consejo Nacional de Investigaciones Científicas y Técnicas (CONICET), Argentina con sede de trabajo en el Centro de Investigaciones Sociales/IDES-CONICET. Miembro del Equipo de estudios en Políticas y Juventudes (Instituto Gino Germani, UBA) e integrante de los proyectos de investigación PICT 2012-1251 (2013-2015) «Activismo y compromiso político juvenil: un estudio sociohistórico de sus experiencias políticas y militantes» dirigido por la Dra. Melina Vázquez.

1 Este artículo se basa en los hallazgos de la investigación doctoral finalizada: «Después de la Noche. Participación en la escuela y movimiento estudiantil secundario: Provincia de Buenos Aires, 1983-2013». La misma fue realizada gracias a una beca doctoral interna del CONICET (Consejo Nacional de Investigaciones Científicas y Técnicas, Argentina). El diseño metodológico de la investigación combinó un relevamiento cuantitativo de corte descriptivo, el análisis documental y un abordaje cualitativo. De este modo, para reconstruir quienes, cuantas y cómo son las organizaciones de estudiantes secundarios en la contermporaneidad, se realizó un relevamiento «desde cero» a partir de la red social Facebook, y se analizó el contenido de los perfiles de 42 organizaciones estudiantiles de segundo grado. Además, se realizaron entrevistas en profundidad a militantes, tanto del espectro kirchnerista, de izquierdas y coordinadoras independientes (total: 20). Para reconstruir lo acontecido en las etapas 1983-90 y 1991-2008 se realizó un análisis de documentos: a) periódicos de circulación nacional; b) publicaciones políticas (revistas y panfletos) y c) el análisis del archivo de los informes de inteligencia policial de la dirección de inteligencia de la policía de la provincia de Buenos Aires (250 fojas) y se complementó (Carnovale, 2007) con d) Entrevistas testimoniales a ex militantes secundarios y ex dirigentes estudiantiles. 


\title{
O MOVIMENTO ESTUDANTIL SECUNDARISTA NA ARGENTINA DEMOCRÁTICA. UM PERCURSO POSSÍVEL POR SUAS CONTINUIDADES E Reconfigurações. Provincia de Buenos AIres, 1983 - 2013
}

\begin{abstract}
RESUMO
Este trabalho tem como objetivo mostrar o percorrido seguido pelo movimento estudantil secundarista na Argentina durante 30 anos de democracia. Apresentamos como hipótese interpretativa que as mudanças em sua conformação e maneira de agir foram atravessadas pelas articulações e desarticulações das identidades políticas mais amplas no marco da entrada em vigor e crise do projeto econômico neoliberal. A análise evidencia como e por que esta forma de participação política juvenil oscilou entre a recusa e a ressignificação da política institucional/partidária; como assim também as implicações disto em seus contextos de ação coletiva e demandas.
\end{abstract}

PALAVRAS CHAVE: POLÍTICA E JUVENTUDES, ESCOLA SECUNDÁRIA, ORGANIZAÇÕES ESTUDANTIS

\section{THE HIGH SCHOOL STUDENT MOVEMENT IN DEMOCRATIC ARGENTINA. A POSSIBLE ROUTE FOR ITS CONTINUITIES AND RECONFIGURATIONS. Buenos Aires Province, 1983 - 2013}

\begin{abstract}
This work is firmly committed on showing the path followed by the high school student movement in Argentina throughout 30 years of democracy. The formulated interpretative hypothesis is that, changes in its conformation and acting have gone through the articulations of the widest political identities within the framework of implementation and crisis process of the neoliberal economic project. The analysis gives a clear insight into the reasons and motivations why this sort of youth political participation have alternated between rejection and resignification of institutional politics as well as its implications in their collective frameworks for action and demands.
\end{abstract}

KEY WORDS: POLITICS AND YOUTH, HIGH SCHOOL, STUDENT ORGANIZATIONS 


\section{DESPUÉS DE LA NOCHE: LOS SECUNDARIOS EN LA TRANSICIÓN}

LUEGO DE SIETE AÑOS de terrorismo de Estado $^{2}$ y una guerra contra Gran Bretaña, el gobierno democrático electo en 1983 se propone refundar la sociedad sobre nuevas bases estableciendo una frontera con el pasado dictatorial y autoritario (Aboy Carlés, 2001). Para el alfonsinismo, ${ }^{3}$ esta refundación implicaba la práctica y la promoción de las instituciones democrático republicanas no solo a nivel estatal/gubernamental, sino en todo el campo social. De la mano de ello, se trataba de fortalecer la legitimidad de la democracia formal, pero también la civil, lo cual incluía la promoción de las libertades individuales y la implementación de mecanismos democráticos en los más diversos ámbitos sociales. Así, la reivindicación de los derechos individuales (el divorcio, la oposición al servicio militar obligatorio, la libertad de opinión e información), tuvieron un lugar destacado en la agenda pública (Sidicaro, 2013).

El compromiso del nuevo gobierno por esclarecer los crímenes perpetuados años antes y juzgar a la junta militar fue acompañado por un importantísimo sector de la sociedad civil. A la vez, el fuerte antimilitarismo instalado redundó en consensos políticos entre actores muy diversos, más que necesarios para reconstruir las instituciones (Sidicaro, 2013).

Las juventudes políticas no fueron una excepción. De hecho, uno de los rasgos sobresalientes en cuanto a la participación de los jóvenes en estos años fue la construcción de espacios políticos basados en la acción conjunta de diversas identidades político partidarias unificadas en ciertas causas y marcos comunes. Esta «vocación» por los acuerdos básicos tiene como hecho fundante la «marcha por la paz y la democracia» convocada en la Ciudad de Buenos Aires y replicada en distintos puntos del país por la MOJUPO ${ }^{4}$ el 2 de julio de $1983 .{ }^{5}$ Otras movi-

2 La última dictadura militar, autora del terrorismo de Estado se mantuvo durante el período 1976-1983.

3 Nos referimos al gobierno y a la línea de pensamiento liderada por el presidente electo Raúl Alfonsín, perteneciente al partido radical (UCR).

4 Hacia fines de la dictadura militar e se crea el Movimiento de Juventudes Políticas (MOJUDO), integrado por las ramas juveniles de los principales partidos políticos por entonces existentes.

5 Cfr. «Dueños de nuestro futuro»; y «Por la paz, contra el golpe y los condicionamientos: imponer la democracia a toda costa» en Revista «Aquí y ahora la juventud» Segunda Época Nº19 del 6 al 19/7/1983; 
lizaciones fueron muy importantes: las marchas por los derechos humanos, ${ }^{6}$ la multitudinaria marcha contra el golpismo en Abril de $1985,{ }^{7}$ y las protestas contra el FMI y el pago de la deuda externa. Varias de ellas fueron organizadas directamente por jóvenes. ${ }^{8}$ Las brigadas de solidaridad estudiantil con la revolución sandinista (Fernández Hellmund, 2010), las misiones solidarias a las provincias del norte argentino, la participación de secundarios y universitarios de distintos signos políticos en eventos internacionales — como el Festival de la juventud y los estudiantes en Moscú- ${ }^{9}$ fueron otros espacios de actuación común entre jóvenes de identidades partidarias diversas. Sin duda, se instala un amplio consenso en la defensa del régimen democrático, voluntad por constituirlo, y un esfuerzo por poner en práctica principios de convivencia acordes con él. La idea de adherir y respetar «las reglas del juego» — diagnosticaban- era el único camino para la supervivencia de una democracia amenazada aún. Esto aparece fuertemente en todos los testimonios de los entrevistados, donde se observa una suerte de conciencia generacional en torno a una suerte de responsabilidad histórica que parecían asumir con entusiasmo. ${ }^{10}$

«Contra la antipatria financiera» en Revista «Aquí y ahora la juventud» Segunda época número sin fechar y sin numerar (junio de 1984).

6 Tal es el caso de la marcha multisectorial y multipartidaria que acompañó la entrega del informe de la CONADEP.

7 Cfr. «Alfonsín convocó al país a poner en marcha una economía de guerra», Tiempo Argentino, 27 de abril de 1985; «Aunque una unánime coincidencia en defensa de la democracia, hubo algunas críticas al mensaje», Tiempo Argentino, 27 de abril de 1985; «De frente a la democracia» en Revista «Aquí y ahora la juventud» Segunda Época Nº61 del 3/5 al $14 / 5$ de 1985 .

8 Cfr. «Contra la antipatria financiera» Revista «Aquí y ahora la juventud» Segunda época número sin fechar y sin numerar (junio de 1984); «El pueblo contra el fondo» Revista «Aquí y ahora la juventud» Segunda Época N63, del 29/5 al 11/6/1985.

9 El festival de la juventud y los estudiantes es un evento que se realiza cada tres o cuatro años desde la segunda mitad del siglo XX y es convocado y organizado por la Unión Internacional de los Estudiantes. Su tendencia es de izquierda. En 1985, se desarrolló en la ciudad de Moscú su edición Nº12. El festival tuvo discontinuidades tras la caida del muro de Berlín.

10 Ello apareció en los testimonios de Lorena (militante de la juventud radical de la rama secundaria en la ciudad de La Plata entre los años 1986 y1989), Ariel P. (militante de la juventud peronista, Unión de estudiantes secundarios de la ciudad de La Plata entre 1985 y 1989), Ariel 
Por otra parte, emerge un protagonismo «novedoso» - en cuanto a la fortaleza de liderazgos y adhesiones - en el campo de las juventudes políticas: la Juventud radical. El politólogo Vicente Palermo (1987) planteaba - de modo contemporáneo al fenómeno - una interesante hipótesis acerca de ello. Según el autor, este crecimiento se debió a una interpelación exitosa de la propuesta del alfonsinismo que «enganchaba» con ciertas características de las subjetividades o culturas juveniles. Fundamentalmente, la juventud oficialista encarnaba una propuesta distanciada del lenguaje revolucionario que evocaba prácticas violentas, o dicotomías como «oligarquía versus pueblo» ambas rechazadas por los jóvenes de ese entonces.

No obstante, nuestro análisis observa que el lenguaje democrático no fue monopolio de las agrupaciones radicales. El análisis de la prensa de la juventud de izquierdas, como así también el testimonio de entrevistados de procedencias y militancias de diverso tipo, evidencian que la adhesión a practicar la democracia estuvo presente en todas las juventudes políticas. Por ejemplo, en un acto de la rama secundarios de la Federación Juvenil Comunista, realizado en noviembre de 1982 bajo el lema «democracia en los colegios y en el país», se exhortaba a los jóvenes secundarios a formar sus centros de estudiantes y participar en la escuela, uniéndose «en las diferencias» para pelear por la participación y los derechos de los estudiantes a partir de «caminos variados».

Impulsando los campeonatos deportivos, recibiendo cada primavera con los grandes recitales de rock de los secundarios, acompañando a los amigos católicos por la paz hasta Luján, peleándole a las dificultades para que salga el primer número de la revista subterránea de cualquier colegio. Nunca dejamos de luchar y así estuvimos con los primeros petitorios que circularon por las aulas, como para ir queriendo. Así nos sorprendimos y nos alegramos al descubrir, en nuestra propia división, al compañero peronista, al radical, o al intransigente, y nos alegramos también al presentarnos como comunistas al docente abierto. ${ }^{11}$

B. (militante del peronismo renovador en el partido de Vicente López entre 1985 y 1989) y Ernesto (militante de la Federación Juvenil Comunista y ex presidente de la Federación de Estudiantes Secundarios de la Ciudad de Buenos Aires) entre los años 1983 y 1987). La idea se reitera en diversas publicaciones, tanto de agrupaciones políticas como en los diarios.

11 Cfr «Soy secundario, soy comunista, por un mundo mejor» en Revista «Aquí y Ahora la Juventud» Segunda época No6, del 2 al 15 de diciembre de 1982 (última página). 
Así, mientras muchos de los jóvenes secundarios intentaban construir centros de estudiantes y organizaciones de segundo grado - incluso ya desde fines de 1982 - ${ }^{12}$ para el mundo adulto el desafío parecía ser qué tipo de política y participación serían admisibles en la escuela secundaria de la democracia.

Retomamos entonces la explicación de Enrique (2011), quien sostiene que el gobierno alfonsinista buscó dejar fuera tanto al sujeto apático/desinteresado, como a aquel «revolucionario» forjado en los '60 y los '70. En cambio, postuló la imagen de un joven solidario, emprendedor, comprometido y dispuesto a aprender y practicar los mecanismos democráticos. Esto se tradujo en la normativa que propuso para los centros de estudiantes secundarios. La resolución 3/84, primera norma que los habilita y regula, reemplaza el término centros de estudiantes por asociaciones estudiantiles. Allí, la prohibición de sostener posturas político partidarias era clara y explícita. La puesta en vigencia de dicha resolución y sus normativas complementarias motivó un fuerte rechazo por parte de los estudiantes. En 1984, la concurrida marcha de estudiantes pertenecientes a colegios de la ciudad de Buenos Aires y del gran Buenos Aires («marcha por los derechos de los estudiantes secundarios») ${ }^{13}$ fue acompañada por la entrega de un petitorio. Pidieron fundamentalmente el reconocimiento de los centros de estudiantes como órganos de representación gremial, la democratización de las escuelas y otras cuestiones relativas a las condiciones de cursada como el boleto estudiantil y rebajas en libros y útiles. En el comunicado de prensa que elaboraron, señalaban «Queremos una escuela en la cual podamos opinar y participar, que sintamos como propia» ${ }^{14}$. Así, el primer gran marco del MES en estos años tuvo que ver con la libertad de agremiación y el derecho a hacer política; lo cual implicaba el reconocimiento de su legitimidad como representantes de un actor específico, gremial, y no un permiso para llevar adelante «emprendimientos». Esto se constituyó como una reivindicación compartida por diversas corrientes políticas. Como bien diagnosticaban,

12 Cfr. Berguier, Hecker y Schiffrin (op. cit.); «Un fin de año muy particular» en Revista «Aquí y ahora la juventud» Segunda Época No7.

13 Cfr. Para los organizadores, la marcha fue de 5000 jóvenes, mientras que para los diarios, de 2000. Cfr. «Petitorio de secundarios», Clarín, 9 de julio de 1984; «Festiva marcha de 2000 jóvenes», Clarín, 9 de julio de 1984.

14 Cfr. «Queremos sentir la escuela como propia» en Revista «Aquí y ahora la juventud» Segunda Época N²0. 
era evidente que quedaban fuera de un proceso que sí incluiría a los estudiantes universitarios (Berguier, Hecker y Schiffrin, 1986) y desde ya, a los otros mayores de edad. Durante ese año, estas movilizaciones continuaron. Aún para los jóvenes de la Juventud radical (perteneciente al partido gobernante), la reglamentación resultaba preocupante y se pronunciaron críticamente al respecto. ${ }^{15}$

El pedido por la democratización refería además a un proceso que debía llegar al interior de las escuelas. Ello tuvo que ver con tres cuestiones. En primer lugar, con la denuncia concreta a rectores y docentes que habían apoyado a la dictadura, o que tenían sospecha de haber sido «colaboracionistas». En segundo lugar, con la lucha en torno a la abolición de prácticas consideradas autoritarias, represivas o irrespetuosas de los derechos individuales de los estudiantes: las formas de vestimenta o presentación personal exigidas, la arbitrariedad de ciertas prácticas docentes (método de sanciones y criterios de evaluación y aprobación). En tercer lugar, la democratización escolar incluía el apoyo para proponer y organizar actividades y debatir sobre temas diversos de interés de los jóvenes, incluyendo cuestiones «políticas» o polémicas.

Luego de las protestas de los estudiantes más movilizados, esta primera normativa fue cambiada en algunos puntos y se reconoció el carácter de los centros como órgano de representación estudiantil, aunque se mantuvo la prohibición de expresión de identidades políticas. A nivel provincial, la normativa (válida para las escuelas bajo su potestad) mantiene estos últimos lineamientos: representar intereses sí, pero no «mezclar la política» en la vida escolar.

A pesar de estas limitaciones, lo cierto es que desde el gobierno se propugnaron notorios cambios en pos de la democratización, los cuales incluían la promoción del respeto a los derechos de expresión de los jóvenes y de ser escuchados. La Secretaría de Educación (nacional) se dirigió a los rectores de las escuelas solicitando «afianzar las características propias de un liderazgo democrático, estimular en los docentes actitudes democráticas, con respeto hacia los alumnos, tratando de modificar aquellas que fueran autoritarias o rígidas y recrear el concepto de relación docente alumno en que ambos sean protagonistas». ${ }^{16}$

15 Cfr. «Reclama cambios en planes educativos la Juventud Radical». Tiempo Argentino, 21 de agosto de 1984.

16 «Programa para democratizar el ciclo medio». Tiempo Argentino, 24 de agosto de 1984. 
Otro rasgo central de la configuración del escenario para la participación de los secundarios tuvo que ver con el miedo ${ }^{17}$ en no pocas situaciones. Durante el juicio a las Juntas, se produce una ola de amenazas de bomba en distintas escuelas secundarias, sobre todo en la ciudad de Buenos Aires pero también en La Plata y en el conurbano. El caos y el temor desatado produjeron que el presidente decretara el estado de sitio por 60 días. ${ }^{18} \mathrm{Se}$ sabía que los causantes de estos hechos eran grupos de tareas (sectores militares y otros de procedencia «mixta») que enviaban claros mensajes de oposición y de amenazas al gobierno y a los juicios. Frente a esto, las movilizaciones de colectivos diversos coincidieron en un marco común: defender la institucionalidad y luchar contra los golpistas. Cierta atmósfera de miedo y sensación de fragilidad de la democracia se extendieron durante todo el gobierno alfonsinista, y por supuesto, repercutió sensiblemente en los secundarios que participaban y especialmente si lo hacían desde algún tipo de militancia político partidaria. Si bien padres y docentes expresaban preocupación, ello no implicó la desmotivación. La impresión de estar construyendo algo importante y fundacional, como mencionamos, convivía con el temor y con aquellos obstáculos que en no pocas ocasiones ponían directivos o determinados docentes.

Un segundo marco de acción colectiva se articuló en torno a demandas por el presupuesto educativo y la mejora en las condiciones estudiantiles. La Federación de Estudiantes Secundarios (FES) de la Capital y otras federaciones del conurbano realizaron una multitudinaria marcha que se llevó a cabo el 29 de julio de 1985, en la que participaron diez mil estudiantes. ${ }^{19}$ El pedido por el aumento de presupuesto no era una demanda aislada: se basaba en la crítica a las exigencias del fondo monetario internacional. El gobierno no había logrado negociar ciertos términos de pago de la deuda externa, y había anunciado meses antes «la economía de guerra». De este modo, los jóvenes reclamaban: aumento del presupuesto educativo — «hasta el $25 \%$ que señala la UNESCO»—, carnet estudiantil (descuentos y beneficios) y el

\section{Referido por los entrevistados.}

18 Cfr. «Interior precisó el alcance sobre el decreto de estado de sitio»; «Atentado a una joven y alarma en varias escuelas»; «Manifestación en repudio a la ola de violencia»; «Veintinueve colegio recibieron amenazas de presuntas bombas». Tiempo Argentino, 26 de octubre de 1985.

19 «Golpes y amenazas a un estudiante secundario». Clarín, 5 de julio de 1985. 
boleto escolar. El petitorio presentado diagnosticaba una «crisis del presupuesto educativo» que se debía a estos planes recesivos. Las coordinadoras de Capital y Provincia continúan separadas organizativamente, pero marchan juntas

Por último, los estudiantes pidieron fuertemente una renovación curricular. Las críticas se dirigían a los contenidos vigentes influenciados por la dictadura y a la lejanía y antigüedad que vislumbraban en función de las necesidades verdaderas del país; como así también a los métodos pedagógicos que utilizaban los docentes. Esto era compartido por distintas agrupaciones políticas, y se planteaban en base a una lectura similar de los contenidos de la educación. En 1985, los estudiantes secundarios radicales, en el congreso citado, exigieron en su documento final un cambio en los planes de estudio dado que «estos no están ni por asomo con la renovación científico y tecnológica que vive el mundo» y que «tal reforma puede contemplar las genuinas necesidades del país y tender a un profundo sentido nacional y latinoamericano». Asimismo, se pronunciaron a favor de «una enseñanza con sentido popular y fomentar el acceso a las escuelas de los más pobres mediante becas, bibliotecas populares, subsidios masivos, y todo otro tipo de medidas que contribuyan a que todos puedan recibir los beneficios de la educación». Los jóvenes de la UES ${ }^{20}$ platense escribían en el diario jotapé la necesidad de modificar los contenidos, e ir hacia una «verdadera educación nacional y popular, revolucionaria». Planteaban un cuestionamiento hacia «repetir de memoria lo que dice un libro que ni siquiera está actualizado» (JOTAPÉ:60). ${ }^{21}$ Los secundarios de la FJC también coincidieron en diversas editoriales en estos reclamos, inclusive en el pedido de la reinstalación de la materia ERSA $^{22}$ tal como se programaba en $1973 .{ }^{23}$ Contraponían esta materia a los programas de estudio arcaicos, de mala calidad y disciplinadores expresados en bibliografía de Educación Cívica. Estos contenidos vetustos y autoritarios debían ser reemplazados por una educación verdaderamente «nacional y popular». En sí, desde distintas perspec-

20 Agrupación encolumnada en el peronismo de izquierda.

21 Cfr. Revista JOTAPÉ publicada el 14-05-1989.

22 Estudio de la Realidad Social Argentina, materia creada durante el breve gobierno de Héctor Cámpora (gobierno de orientación peronista electo tras el fin de la dictadura militar del período 1966 -1973).

23 Cfr. «La FJC propone» en Revista «Aquí y ahora la juventud» Segunda Época No18. 
tivas, el pedido de cambios curriculares se dio en términos de actualización, renovación o adecuación a una escuela democrática, nacional, popular y moderna o científica.

\section{DEFENDER LA EDUCACIÓN, CUESTIONAR LA POLÍTICA: 1990 - 2005}

Los marcos y demandas, y las formas de organización de los estudiantes secundarios presentarán enormes rupturas a partir del año 1990. Tras la asunción del gobierno menemista, la adopción de políticas antipopulares, una reforma educativa en base a lineamientos neoliberales que modificaba toda la estructura del sistema educativo, ${ }^{24}$ las leyes de obediencia debida, punto final $^{25}$ y el indulto, sellaron una crisis definitiva entre los jóvenes militantes y las identidades partidarias. Estos hechos permiten dimensionar un significante central que emerge - como categoría nativa - a la hora de dar cuenta de los cambios de este vínculo: la «traición». Por un lado, la juventud radical había acudido al llamado a defender la democracia y condenar a la junta militar, y a plantear un modelo económico popular (como habían sido las primeras propuestas del gobierno alfonsinista). Las juventudes vinculadas al peronismo, por su parte, habían apoyado la candidatura de Carlos Menem, quien a los pocos días de asumir dejó en claro que el modelo económico del nuevo gobierno estaría alineado a intereses

24 Dicha reforma educativa consistió en una serie de políticas, leyes y medidas que se plasmaron en la denominada Ley Federal de Educación, sancionada en 1992. Esta modificó estructuralmente el sistema educativo. Implicó la transferencia desde la administración estatal central hacia las provincias de distintas responsabilidades administrativas y de financiamiento y cambió la organización de los ciclos de enseñanza, entre otras cuestiones. La ley, a la que muchos autores consideran como una reforma de corte neoliberal y anclada a recomendaciones de organismos multilaterales de crédito, fue muy resistida por los sindicatos docentes y organizaciones estudiantiles. Fue reemplazada en el año 2006 por una nueva ley nacional de educación.

25 La ley de obediencia debida (sancionada en el año 1987 tras un alzamiento militar) estableció que los delitos cometidos por los miembros de las Fuerzas Armadas cuyo grado estuviera por debajo de coronel no serían penalizables. La ley de Punto final, complementaria a la anterior, estableció la prescripción de los delitos contra los imputados como autores penalmente responsables de la desaparición y asesinato de personas. 
del establishment local y a los organismos internacionales. El proyecto de reforma educativa, iba entonces en esta línea y tanto los sindicatos docentes como las organizaciones estudiantiles lo leyeron inmediatamente. Por otra parte, los partidos y movimientos de izquierda atravesaban un contexto de división interna. Para sintetizar, encontramos una muestra interesante de esta sensibilidad inaugural, - pero que recorrerá la década - en un panfleto del año 1992, en una de las publicaciones de la rama secundarios de la agrupación juvenil Venceremos:

\begin{abstract}
Nosotros somos la generación que vive la mentira en carne propia de la democracia formal, de su forma trucha de hacer política. De su corrupción y no fuimos deslumbrados ni por hechos (como nuestros abuelos en los primeros gobiernos peronistas) ni por el verso y la capacidad de oratoria de Alfonsín (como nuestros hermanos mayores). Esto produce actitudes contradictorias pero necesarias a la hora de protegernos del forreo. Mientras indirectamente esto influye en que sólo creemos en nosotros mismos. ${ }^{26}$
\end{abstract}

En síntesis, los adolescentes que comienzan a participar políticamente en estos años atravesaron experiencias que los marcaron como una generación política. Estas son la ya mencionada reforma educativa, la desconfianza y decepción hacia los partidos políticos tradicionales, la «criminalización» y la represión hacia los jóvenes por parte del Estado y la emergencia de formas de expresión de compromiso político vinculadas a la aparición de nuevos sujetos y causas (desocupados, hijos y familiares de desaparecidos, colectivos contra la violencia policial, entre otros). Junto con ello, se consolidan nuevos repertorios de acción colectiva (Schuster, 2005) y formas de construcción de la identidad política a partir de una narrativa autonomista (Svampa, 2010).

Así, la participación de los estudiantes secundarios tiende a seguir esta lógica. Los testimonios de los entrevistados, como así también el análisis de las publicaciones de la época nos muestran una doble dimensión. Por un lado, aparece una percibida «apatía» para conformar centros de estudiantes en las escuelas y un rechazo generalizado a «todo lo que suene político». A la vez, es clara la emergencia de coordinadoras estudiantiles y núcleos de militantes secundarios activos que construye-

26 Cfr. Documento para la discusión del $1^{\circ}$ Encuentro Nacional de la Juventud (secundarios) de la Agrupación Juvenil Venceremos, septiembre-octubre de 1992. 
ron colectivos de protesta (fundamentalmente en contra de la reforma educativa), pero que también fueron capaces de acompañar a otros movimientos sociales. Las organizaciones estudiantiles de secundarios se conforman no ya a partir de frentes con base en identidades partidarias, sino a partir de organizaciones independientes ancladas en el ámbito local (ciudades, regiones).

A partir de nuestro análisis, hemos encontrado cuatro núcleos que construyeron la «agenda» del MES. Es posible identificar una identidad - aún con diferencias - en los reclamos y en los oponentes: la oposición a la reforma educativa como amenaza a la educación pública, el reclamo de justicia frente a los crímenes de la dictadura impunes, la protesta por la criminalización y represión hacia la juventud («gatillo fácil») y el reclamo por problemas edilicios y/o de infraestructura. ${ }^{27}$ Junto con ello, los oponentes y responsables fueron identificados como el estado nacional, provincial, los organismos internacionales de crédito y la figura de «los políticos». Como contrapartida, las agrupaciones estudiantiles de segundo grado encuentran nuevos referentes identitarios y aliados: los organismos de derechos humanos (principalmente Madres, Abuelas, HIJOS y CORREPI) ${ }^{28}$ movimientos de trabajadores desocupados, sindicatos docentes y ciertas bandas de rock.

Como hemos mencionado, la oposición a la reforma educativa y la situación de amenaza parecieron funcionar como «aglutinantes» de diversos actores y espacios ideológicos. A pesar de la variabilidad de agrupaciones políticas, coordinadoras «independientes», agrupaciones espontáneas de padres y alumnos, es posible mostrar un marco de diagnóstico, pronóstico y motivación (Hunt, Snow y Benford, 1994) relativamente estable. Así, el proceso de reforma educativa fue leído por los secundarios como un ataque total al carácter público de la educación, vinculando su publicidad a la gratuidad — se destacaba el peligro constante de arancelamiento y la intención privatizadora- - y a su calidad. Para estos actores, el vaciamiento y la pérdida de calidad tienen como principal indicador la intención de desinversión, el cual se reflejar en un

27 Para sostener este argumento, hemos contabilizado acciones de protesta y eventos a partir de un del archivo de informes policiales de provisto por la Comisión Provincial por la Memoria.

28 La CORREPI se funda, sin fecha precisa hacia fines de la década de los 1980. Se define a sí misma como «una organización política que activa en el campo de los Derechos Humanos, al servicio de la clase trabajadora y el pueblo, con especificidad frente a las políticas represivas del Estado». 
recorte presupuestario y en los bajos salarios docentes. La reforma es sinónima de querer gastar menos en la educación.

La privatización aparece con dos figuras: aquella que sostiene que el objetivo es favorecer a las escuelas privadas, o bien, aquella que sostiene que el objetivo es que los particulares (padres) paguen por la educación. La segunda cuestión refiere a otros cambios que afectarían fuertemente a la calidad educativa: la reforma curricular. Esto tiene su caso más emblemático en los cambios de los planes de estudio de la educación técnica, repensada para formar en «competencias generales» para el mundo del trabajo. Aquí la lectura fue que se buscaba alinear la educación a las «necesidades del mercado». En definitiva, las organizaciones de estudiantes secundarios en el proceso de construcción de marcos, engloban la reforma educativa en una política privatista y «entreguista», dado que se la vincula directamente con la obediencia a las directivas de organismos internacionales de crédito. En síntesis, este marco es de total oposición y su respuesta será «en defensa de la escuela pública», apoyando el reclamo salarial docente e incluyendo esta cuestión como una de las pruebas empíricas de lo que se proponen. Obviamente, la protesta educativa se enlaza con una crítica general hacia toda la política económica y las privatizaciones de los servicios públicos.

Otro núcleo importante de demandas tuvo que ver con la represión. Esto se incluía en un marco crítico del accionar policial/estatal: los jóvenes denunciaban una intencionalidad claramente represiva dirigida hacia ellos. Desde el retorno a la democracia el accionar violento policial contra los jóvenes - y especialmente, si eran pobres - serán una constante. La denuncia contra el «gatillo fácil» se constituyó como parte de las reivindicaciones de algunos sectores del movimiento estudiantil desde momentos tempranos de la década. ${ }^{29}$ Cabe destacar que además de los asesinatos policiales, el clima de sospecha se extendía a ámbitos más cotidianos: «la juventud en la noche» era uno de ellos. En 1996, el entonces gobernador Duhalde firma un decreto por el cual se limita el horario de funcionamiento de locales bailables hasta las tres de la madrugada. ${ }^{30}$ La represión en las manifestaciones y protestas también eran

29 Cfr. Panfletos archivos DIPPBA; Documento para la discusión del «Esta Argentina no tiene lugar para nosotros» en Por otra Argentina. Con el ejemplo y el aguante del Ché. Documento de la Juventud Venceremos, Corriente Nacional Patria Libre, 1993; entre otros.

30 Cfr. «Los chicos le arrancaron una hora más a Duhalde». Página 12, 2 de abril de 1998. 
frecuentes, al igual que las detenciones arbitrarias, particularmente en recitales y eventos nocturnos. Los reclamos no se agotaban en el pedido de justicia por las víctimas de la violencia policial e institucional, sino también, como parte de la visibilización del problema de la discriminación y las «razzias».

Ahora bien, las críticas hacia el accionar policial permearon no solo a sectores del movimiento estudiantil sino a ciertas manifestaciones culturales de los jóvenes en general. Durante la década de los 1990, el rock nacional experimentó la emergencia de ciertas bandas con discursos y estéticas diferentes en relación con las predominantes en la década precedente (Semán y Vila, 1999; Citro, 2008). Tanto desde el rock barrial (Ibid) como desde otras bandas con importante convocatoria y con un componente de crítica social (Citro, 2008), la denuncia de este accionar policial se constituyó como un significante importante en su lírica. En una palabra, el «discurso antiyuta» ${ }^{31}$ era parte de la construcción de determinadas adscripciones identitarias juveniles (Reguillo Cruz, 2003) en el rock, pero también en el fútbol.. En una palabra: el universo de significados de este rock barrial, popular, «crítico» y antiyuta, tienen una afinidad insoslayable con ciertas demandas del MES.

La cercanía entre el mundo del rock y los marcos del movimiento secundario no consistió solamente en ser un consumo cultural de los jóvenes (efectivamente, era la música que escuchaban los entrevistados), en una afinidad discursivo ideológica o de demandas en común. Concretamente, se registran actividades organizadas en común. En el caso de La Plata, algunas de estas bandas más reconocidas participaron de festivales organizados por el movimiento estudiantil. La CORREPI también organizaba festivales en conjunto con estudiantes secundarios, puntualmente para conmemorar y pedir justicia por las víctimas $^{32}$ Las revistas de diferentes partidos de izquierda y de izquierda independiente, también muestran esta ligazón a través de la publicitación de festivales, o bien, publican noticias que plantean de-

31 «Yuta» es un argentinismo — proveniente del lunfardo porteño- para referir a la policía. «Antiyuta» es una expresión utilizada para referir a la actitud antipolicía.

32 Cfr. «Rock y bronca en el aniversario de la muerte de Walter» en Revista OKTUBRE. Revista de la Juventud Socialista del MST. N4, abril de 1995; «Nadie investiga la muerte de un joven en un recital de rock», Clarín, 10 de mayo de 1996. 
bates en torno - por ejemplo - a las actuaciones de estas bandas ${ }^{33}$ Para los militantes activos, esta cercanía servía para construir afinidades con «los pibes» (compañeros de escuela) que no tenían interés en participar políticamente, pero que podían engancharse en torno a estas «movidas» puntuales. Por último, los repertorios de acción estarán vinculados fuertemente a acciones con visibilidad pública (marchas, radios abiertas, «mesas», festivales, recitales). Desde el punto de vista de la política educativa, durante estos años, las normativas no presentaron cambios para la representación estudiantil. Continuaban vigentes los reglamentos producidos en los 1980 .

La crisis de 2001 y la primera etapa de los gobiernos kirchneristas (2004 y 2007) no implicaron una reconfiguración de los formatos organizativos y las identidades estructuradas en torno a las agrupaciones independientes y de izquierdas. Los testimonios de los entrevistados en estos años, como así también el análisis de documentos evidencian un momento de latencia (excepto en el año 2005, donde se producen movilizaciones en protesta por cambios en el régimen de evaluación/aprobación de la escuela secundaria); como así también se sostienen las críticas al modelo neoliberal presente en la educación. La nueva ley nacional de educación, sancionada en 2006, no fue un hecho que produjera una fuerte movilización opositora unánime por las organizaciones que sí funcionaban. Ello cambiará fuertemente en la etapa posterior.

\section{RECONFIGURACIÓN Y FRAGMENTACIÓN}

Consideramos el año 2009 como un punto de quiebre y rupturas en las organizaciones del movimiento secundario a partir de la consideración de algunos acontecimientos relevantes que creemos marcan un momento distintivo dentro de la postconvertibilidad. Ello redunda en determinadas y diferenciales condiciones de posibilidad dadas a la participación en la escuela y de la construcción de identidades políti-

33 Cfr. «Porque el tiempo, el tiempo no para», Revista OKTUBRE. Revista de la Juventud Socialista del MST, Año 1, Nº1, 1993. «La renga», Revista La Caldera, Unión de Juventudes por el Socialismo, 8 de marzo de 1996. «El arte y la juventud: sobre música y libertad», Revista La Caldera, Unión de Juventudes por el Socialismo N²4, 16 de septiembre de 1997. «El festival de los privatizadores», Unión de Juventudes por el Socialismo N³2, 12 de marzo de 1999. 
cas juveniles y estudiantiles en particular. Dichos procesos tienen que ver, por un lado, con factores propios del sistema educativo provincial y por el otro, con ciertos factores vinculados al contexto sociopolítico nacional. Ellos son:

- El impulso - y su impacto - dado a la participación y a la conformación de los centros de estudiantes en la política educativa provincial propugnada a partir de importantes cambios en sus normativas. $^{34}$

- Un conjunto de políticas a nivel nacional específicas destinadas a promover la participación juvenil.

- El crecimiento de las agrupaciones juveniles kirchneristas (Artola, 2009, Pérez y Natalucci, 2012), desde el año 2009 y 2010, lo cual generó un engrosamiento de una militancia juvenil oficialista; pero también la visibilización de otras juventudes partidarias que habían cobrado fuerza en años recientes (Cozachcow, 2013; Vommaro, 2014).

- El incremento cuantitavo de organizaciones estudiantiles de segundo grado en el ámbito provincial, siempre agrupadas por localidad.

Es importante hacer algunas aclaraciones al respecto: en primer lugar, el crecimiento de las organizaciones juveniles kirchneristas, no resulta central porque consideramos que ellas son las «más importantes». Más bien, creemos que la (hiper)visibilidad $-\mathrm{y}$ el crecimiento en númerode una juventud que apoya al partido en el gobierno resulta novedosa desde el retorno democrático. Pero principalmente, dicha irrupción generó un desafío y planteó una disputa a las identidades previas que tenían un protagonismo casi único en el movimiento estudiantil secundario (sobre todo, las agrupaciones de izquierdas). Justamente, las juventudes de izquierda fueron las que quizás más fuertemente respondieron al advenimiento de la «juventud kirchnerista». El asesinato del militante del Partido Obrero Mariano Ferreyra en una protesta sindical desató el reclamo de justicia y la denuncia sobre la vigencia de viejas prácticas sindicales mafiosas, pero también produjo la construcción de un hito simbólico diferenciador. Así, su figura y su militancia se construyeron

34 Dichos cambios se vieron reflejados en modificaciones realizadas en los años 2005, 2009 y 2011. En el año 2013 se sanciona una ley provincial que establece la obligatoriedad de que todas las escuelas secundarias (públicas y privadas) tengan su centro de estudiantes. Para indagar con mayor profundidad estos cambios, cfr. Larrondo, 2014. 
como símbolo de la «verdadera juventud militante», aquella «totalmente independiente del gobierno». De este modo, el número de 2011 de la revista «ujotaese» ${ }^{35}$ tiene como tapa el título «Juventud militante». En ella, la nota central se dedica a denunciar la «cooptación» de la juventud por parte del kirchnerismo, planteando la intencionalidad de «generar un conjunto de 'pichones de punteros` a partir del reparto de planes asistencialistas». La contraposición es clara: la juventud que lucha «no transa» con el estado, su rol es siempre denunciar y salir a la calle a combatir.

Consideramos que estos fenómenos, marcan un período distinto de los precedentes. Este se caracteriza por una militancia estudiantil secundaria fuertemente dividida en identidades políticas antagónicas, dos de ellas vinculadas con proyectos partidarios. De este modo, es posible identificar tres vertientes ideológicas e identitarias que se expresan en las organizaciones de segundo grado. En los próximos apartados daremos cuentas de sus rasgos más notorios.

\section{a) El «proyecto nacional y popular» en la escuela: organizaciones del espectro kirchnerista}

Las organizaciones estudiantiles pertenecientes al espectro kirchnerista suelen iniciarse en el seno de una organización concreta (correspondiente a algunos de los frentes y agrupaciones kirchneristas) que funciona en un partido/localidad y que decide conformar su rama de secundarios. A partir de allí estas adquieren una dinámica propia ligadas a las cuestiones estudiantiles. No obstante, más allá de sus diferencias, presentan un conjunto de elementos discursivos y simbólicos comunes, un repertorio de acciones comunes. Obviamente, su más evidente característica es encolumnarse detrás del «proyecto nacional y popular».

En este sentido, cabe mencionar que ellos están con el partido en el gobierno. Por lo tanto, su participación tiene una característica que pocas veces se repite en el movimiento estudiantil secundario. Esto se refleja en los marcos de acción colectiva, pero primordialmente, en el repertorio de acciones. Además, la construcción de «oponentes» que todo movimiento social conlleva tiene diversas complejidades y desafíos para estos grupos, especialmente, si se trata del Estado.

35 Revista de la Unión de Juventudes por el Socialismo. 
Para estos jóvenes, los objetivos del movimiento estudiantil, la concepción de defensa de la educación pública, la construcción de los problemas educativos, del rol del estudiante secundario y de los oponentes, adquieren su sentido y resignificación desde este gran marco. Así, estar con el proyecto nacional y popular y llevar sus banderas en la lucha por la educación pública implica defenderlo de quienes lo amenazan. La amenaza está representada en el pasado inmediatamente anterior - las políticas de la década del 90- pero también en el presente a través de la continuidad de sus portavoces: partidos políticos de derecha y personas con nombre y apellido, casi siempre, las que estuvieron involucradas en dichas gestiones. Son los señalados como los responsables del vaciamiento, la desinversión y la desigualdad educativa que se produjo principalmente en la década de los 1990. En una palabra, el «neoliberalismo». Allí reside el «diagnóstico» de la situación. En definitiva, los oponentes son los sectores que representan a estas políticas y coinciden con aquellos oponentes que construye el movimiento kirchnerista en general. El «neoliberalismo» como significante, alude a procesos sociopolíticos y a políticas implementadas en un pasado reciente, pero está encarnado en personas concretas del presente («Macri»), actores colectivos («el campo»; «Clarín»). Son oponentes y «actores responsables» (Rivas, 1998) contra los que hay que combatir.

La lucha por una escuela «popular e inclusiva» — tal como la definen-, tiene que ver no solo con reivindicar, sino con defender lo hecho, de lo que siempre se da muestras a partir de la enumeración de «logros» de la gestión de Néstor Kirchner y de Cristina Fernández. Defender lo hecho implica apostar a su ampliación, a lo «por venir» a partir de la «profundización» de estas políticas. Para estos jóvenes, el modelo nacional y popular ya ha mostrado su compromiso con la inclusión educativa - entre otras-, y con la ampliación de formas de participación juvenil. Concretamente, los logros enumerados refieren al programa conectar igualdad, las nuevas escuelas construidas y la ley de «voto joven». Todas estas enumeraciones son incluidas en sus intervenciones públicas.

El llamado a la participación de los jóvenes en organizaciones estudiantiles y centros de estudiantes tiene que ver con «militar el modelo», lo cual interpretan como una continuidad - y a la vez un homenaje- con aquella militancia secundaria de otra generación de jóvenes que «luchaban por una sociedad mejor»: los militantes estudiantiles de la década de 1970 que fueron desaparecidos por el terrorismo de esta- 
do. En cuanto a sus repertorios de acción «defender el proyecto nacional y popular» tiene que ver con:

— «meter el debate político» en la escuela, a través de la organización de debates, charlas o actividades que impliquen la discusión de problemas públicos, principalmente, aquellos que ellos consideran relevantes.

- Organizar y ayudar a otros jóvenes a formar centros de estudiantes.

- Defender la educación pública implica también ocuparse activamente de los problemas de la escuela y hacer cosas por mejorarlas «con las propias manos».

- Ante los problemas edilicios y/o de recursos, propugnan por pedir entrevistas con funcionarios, elaborar cartas, hacer petitorios y recurrir a la protesta callejera en última instancia.

En definitiva, no aparecen críticas estructurales al sistema educativo, ni a las leyes que lo regulan, ni al eje de las políticas educativas - aunque sí a sus posibles amenazas-. Por el contrario, se valoran fuertemente las políticas educativas post $2003 \mathrm{y}$ el rol del movimiento estudiantil es apoyarlas, pero solicitando las mejoras necesarias siempre desde el «diálogo», desde la «crítica constructiva» y desde el «ocuparse». En síntesis, las demandas dirigidas hacia el Estado tienen que ver con obtener mejoras en lo que ya se está implementando y lo que se exigen son «rectificaciones del rumbo» 0 «que estas cosas lleguen».

\section{b) «Una postura totalmente crítica»: el caso de las CUES (organizaciones de la izquierda)}

Durante este período, fueron fortalecidos espacios de coordinación autoproclamados independientes y abiertos a todos los estudiantes, aunque se trata de espacios claramente abiertos y/o impulsados por partidos de izquierda, quien tiene $-\mathrm{y}$ ha tenido- una importante presencia en las organizaciones de secundarios y en las universitarias. Nos referimos principalmente a la UJS (partido obrero), la juventud del PTS, —entre otros, quienes se declaran «totalmente críticas al gobierno». Al igual que en el caso de las agrupaciones kirchneristas, la formación en distintas localidades de las «Coordinadora de estudiantes secundarios» - espacio que surgió en primer lugar, en la ciudad de Buenos Aires-, data de años recientes.

En síntesis, estos espacios llaman a una convocatoria amplia y centrada en los problemas estudiantiles, pero opositora al gobierno 
nacional y provincial. Sus marcos de acción colectiva se constituyen, al igual que en las agrupaciones kirchneristas, en torno a la ciertas demandas «clásicas»: la defensa de la participación de los estudiantes y «hablar de política» en las escuelas, la promoción de la apertura de centros de estudiantes, el reclamo por el derecho a la educación y las «condiciones de educabilidad»; y los derechos humanos. Aunque obviamente, a partir de marcos divergentes.

El marco de diagnóstico, y particularmente, las referencias «reales» que permiten fundamentarlo, ubica a estas organizaciones como espacios de fuerte confrontación y oposición. Ella es doble: frente al Estado - nacional, provincial y local- y frente a las agrupaciones estudiantiles kirchneristas; que serían reflejo de ese Estado. En efecto, se encuentran en clara disputa por representar los «genuinos» intereses estudiantiles.

Los espacios de coordinación de izquierda también construyen interpretaciones y demandas coherentes y en sintonía con los partidos y movimientos sociales de izquierda opositores al partido en el gobierno. Ahora bien, si bien ello no necesariamente se oculta - a nivel de la pertenencia militante de sus miembros - no se explicitan vínculos más orgánicos con partidos. Los jóvenes que participan de estos espacios, expresan fuertemente el carácter «independiente» de las coordinadoras. No obstante, no es difícil observar su ligazón.

Así, sus discursos públicos postulan al período actual, y en particular, en relación con la política educativa, como una continuidad y una profundización del neoliberalismo y de destrucción de la educación pública. Los problemas edilicios que afectan a las escuelas, los problemas con la distribución de viandas, el conflicto salarial docente y el retraso en la entrega de las netbooks, son la prueba empírica de ello. Las políticas educativas del Estado nacional y provinciales son políticas «populistas» que continúan una estructura de explotación, en continuidad con las décadas precedentes. Las intenciones privatizadoras de la educación también se evidencian a partir del mantenimiento de los subsidios al sistema privado. En definitiva, los problemas presupuestarios son un nuevo ajuste que está llevando a cabo del gobierno provincial y el gobierno nacional. Así, los reclamos y demandas en torno a la cuestión edilicia y al programa conectar igualdad se enmarcan en esta visión, y de allí el eslogan del «NO al ajuste de $\operatorname{Scioli}^{36}$ y los K». Por ello, su postura declarada es «totalmente crítica a los dos gobiernos». 
Por otra parte, para ellos, el crecimiento de las organizaciones estudiantiles kirchneristas, no fue el resultado de una participación genuina, sino una estrategia planificada por el gobierno para frenar el proceso de luchas de la verdadera juventud combativa.

Asimismo, estas agrupaciones también realizan un diagnóstico de la situación sobre la participación en las escuelas particularmente interesante. Frente a las normativas provinciales, denuncian la intencionalidad de «regimentar los centros de estudiantes». La regimentación de los centros refiere a uno de los artículos de la normativa vigente que indica que los CE tienen que contar con un profesor asesor. Ello es leído como control para impedir la libre organización política estudiantil.

Para estos jóvenes, el mecanismo de la asamblea y la acción directa son por antonomasia, parte de la identidad estudiantil y de su función. El estudiante secundario debe hacer política con mayúscula, no actividades menores (recreativas, solidarias, «emprendedurismo») y esta política se define «en la lucha». Ella se da dentro de la escuela y fuera de ella, en la calle.

Como venimos sosteniendo, los marcos de pronóstico y motivación vinculados a las organizaciones de izquierda, además de ser diferenciados de las otras organizaciones, presentan una fuerte continuidad con aquellos marcos construidos por las organizaciones estudiantiles en la década del 90. En síntesis, las organizaciones estudiantiles de izquierda construyen su identidad colectiva a partir de una postura crítica hacia el Estado, al partido en el gobierno y la militancia secundaria adherente a él.

Su rasgo más distintivo es la lectura de la continuidad del neoliberalismo en educación, su lectura sobre las políticas educativas como «clientelismo» y un llamado a la acción directa como método de lucha privilegiado, que no se encuentran ni en las organizaciones «K», ni en las que analizaremos en el próximo apartado.

\section{c) Los independientes}

El tercer tipo de organizaciones que encontramos en el presente, son espacios que se autoproclaman abiertamente apartidarios. Construyen su identidad apegados a «los intereses estudiantiles»; «los derechos de los estudiantes y la juventud»y «los problemas de las escuelas». Ello no significa que estén conformados en su totalidad por jóvenes sin militancia. Lo que sí claramente los define es que sus marcos y demandas se construyen sobre tópicos de la definición de los problemas de las escue- 
las, la solidaridad y la «participación» en el ámbito local. Dentro de estas organizaciones las hay de dos tipos: aquellas que construyen una lectura política más amplia (y dentro de ellas hay una importante diversidad) y aquellas destinadas a la concreción de actividades comunitarias, de sociabilidad juvenil y de ayuda a la mejora de las escuelas.

De acuerdo a lo observado, conformar un espacio de coordinación plural puede resultar complejo. Estas coordinadoras, no definen líneas de interpretación unívocas sobre las problemáticas estudiantiles. Asimismo, sus marcos de diagnóstico tienden a individualizar los responsables de cada situación, de cada problema concreto que atraviesa el sistema educativo, particularmente, en el ámbito local (municipal o regional). No se registraron críticas estructurales a las políticas educativas, sino a sus falencias. La mayor parte de los problemas de las escuelas del distrito — que es, recordemos, el núcleo central de su conformación de sus demandas - son vistas como una concatenación de responsabilidades entre las autoridades locales, pero también, los propios directivos y el personal de las escuelas. Por otro lado, sus marcos de motivación tienen un componente reivindicativo: la defensa de los derechos de los estudiantes a organizarse para ser escuchados y resolver estos problemas. Al comprender los problemas de las escuelas a partir de una idea de «co-responsabilidad», la postura crítica hace un esfuerzo por distinguir ámbitos de incumbencia y responsabilización, y en ello sí eventualmente pueden aparecer críticas al estado provincial. Es el enfoque situacional, son «los problemas» y «el enfoque dado a los problemas» - principalmente de la educación - lo que define los posicionamientos ideológico políticos. Ellos están convencidos que tomar una postura rígida o «partidaria» deja de lado a otros jóvenes y resta integrantes. Además, esto imposibilita la confrontación o las alianzas con quienes «sea necesario». Si los problemas lo demandan, se debe criticar al gobernador, al intendente, a los directivos: se gestiona, o se sale a reclamar a quien corresponda.. La tensión referida a qué, quienes, y cómo se critica, es un dilema que se resuelve día a día, y en relación a cada problema. Manejar esta tensión es fundamental para alcanzar «el verdadero objetivo» que los convoca: la mejora de las escuelas y las condiciones estudiantiles, pero también, el aumento de la participación. 


\section{REFLEXIONES FINALES}

Como hemos mostrado, las organizaciones del MES en la actualidad se diferencian fuertemente entre sí a partir de sus ideologías e identidades políticas y las fronteras identitarias que construyen. Esto marca una fuerte ruptura en relación con otros momentos, especialmente con la década de 1990. Este escenario redunda en una fuerte fragmentación: la incompatibilidad de sus marcos genera imposibilidades para la formación de antagonistas y solidaridades comunes. El «neoliberalismo», el «ajuste» la privatización de la educación y los autoritarismos siguen siendo aquello sobre lo cual los jóvenes se movilizan, solo que estos son definidos de diferente manera, son personificados y adjudicados a actores responsables diferentes (y antagónicos) y por ello, se vehiculizan distintas formas de intervención pública. Lo que sí es posible mostrar es la continuidad de un conjunto de reivindicaciones genéricas e históricas («defensa de la escuela pública») y demandas concretas actuales (fundamentalmente, las condiciones edilicias y los recursos materiales de las escuelas) que los estudiantes comparten objetivamente. Pero ellas no alcanzan a constituirse como intereses comunes por lo antes dicho. Este fenómeno, creemos, nos permite reflexionar sobre varias cuestiones. En primer lugar, sobre el retorno (luego de más de veinte años) de las referencias a la política institucionalizada/partidaria como revitalizador e influyente en la conformación del movimiento estudiantil; a la vez que la persistencia de las organizaciones independientes. Creemos que esto muestra que este «retorno» aparece más como una emergencia antes que como «reemplazo». Es decir, los vínculos entre juventudes y política(s) pueden tener «idas y vueltas» a partir del cambio de las coyunturas histórico políticas más amplias. Por otro lado, es indudable que en Argentina este proceso fue de la mano de la erosión de los espacios de convivencia de identidades políticas diferentes. A algunos investigadores esto nos puede colocar en una situación de incomodidad frente a la falta de «unidad» de los estudiantes; mientras reconocemos en esta misma incomodidad un fuerte juicio sobre un «deber ser». En cambio, otra lectura nos invitaría a sostener el signo de pregunta acerca de la complejidad de lo que la democracia implica y significa para estos jóvenes (¿es para ellos un problema la «fragmentación»?); lo que la revitalización de los vínculos con lo partidario - y la polarización ideológica de la Argentina contemporánea - les aportó para la constitución de sus identidades políticas en el marco de su primera experiencia mili- 
tante, qué aprendizajes políticos adquieren y en definitiva, qué rumbos impredecibles tomarán (o retomarán) en los próximos años.

BUENOS AIRES (ARGENTINA), NOVIEMBRE 2014

RECIBIDO: NOVIEMBRE 2014

ACEPTADO: FEBRERO 2015

\section{REFERENCIAS BIBLIOGRÁFICAS}

ABOy CARLÉS, GERARDO (2001): Las dos fronteras de la democracia argentina. La reformulación de las identidades políticas de Alfonsín a Menem. Rosario: Homo Sapiens.

ARtOla, Sebastián (2012): «iEl futuro ya llegó! Notas sobre el kirchnerismo, la juventud y el sujeto político». El ojo Mocho, Año II, №2-3. Buenos Aires.

BERGUIER, R., E. HECKER y A. SCHIFFRIN (1986): Estudiantes secundarios: sociedad y política. Buenos Aires: Centro Editor de América Latina.

CARNOVAlE, Vera (2007): «Aportes y problemas de los testimonios en la reconstrucción del pasado reciente en la Argentina». En M. FRANCO y F. LeVín: Historia reciente. Perspectivas y desafíos para un campo en construcción. Buenos Aires: Paidós.

CitRo, SilviA (2008): «El rock como ritual adolescente. Trasgresión y realismo grotesco en los recitales de Bersuit». TRANS (Revista Transcultural de Música), 12.

COHEN, J. (1985): «Estrategia e identidad: paradigmas teóricos nuevos y movimientos sociales contemporáneos». En Social Research, 52 (4). Traducción en Teoría de los Movimientos Sociales. Cuaderno de Ciencias Sociales, 17 (1988). Costa Rica: FLACSO.

COZACHCOW, ALEJANDRO (2013): «Juventudes partidarias en la Ciudad Autónoma de Buenos Aires: motivos de participación, proyecto colectivo y proyecto individual (2012-2013)». IDES-UNGS (mimeo).

DianI, MARIO (1992): «The Concept of Social Movement». Sociological Review, 40 (1).

ENRIQUE, I. (2011): «La participación estudiantil en la escuela secundaria en la Argentina. Reconstrucción del conflicto en torno al protagonismo político de los jóvenes». Tesis de Maestría en Políticas Sociales. Buenos Aires: Facultad de Ciencias Sociales, Universidad de Buenos Aires.

FERNÁNDEZ HELLMUND, P. D. (2010): «La solidaridad argentina con la Revolución Popular Sandinista. El caso de Partido Comunista de la Argentina. Un análisis en clave antropológica». Trabajo preparado para el Congreso 2010 de la Asociación de Estudios Latinoamericanos. Toronto, Canadá. 
HunT, S., R. BENFORD y D. SNOw (1994): «Marcos de acción colectiva y campos de identidad en la construcción social de los movimientos». En E. LARAÑA y J. GUSFIELD: Los nuevos movimientos sociales. De la ideología a la identidad. Madrid: Centro de Investigaciones Sociológicas.

LARrondo, MARINA (2014): «Después de la noche. Participación en la escuela y movimiento estudiantil secundario: Provincia de Buenos Aires, 1983-2013». Tesis de Doctorado. Los Polvorines: Universidad Nacional de General Sarmiento-IDES.

_ (2012): «El discurso kirchnerista hacia la juventud en contextos de actos de militancia» (inédito).

MCADAM, D., J. MC CARTHY y M. Zald (1999): «Oportunidades, estructuras de movilización y procesos enmarcadores: hacia una perspectiva sintética y comparada de los movimientos sociales». En MCADAM, MCCARTHY y ZALD (comp.): Movimientos sociales: perspectivas comparadas. Madrid: Istmo.

NATAluCCI, ANA y GERMÁn PÉREZ (2012): «Introducción: el kirchnerismo como problema sociológico». En A. NATAluCCI y G. PÉREZ (comps.) Vamos las bandas. Organización y militancia kirchnerista. Buenos Aires: Trilce.

PALERMO, ViCENTE (1987): «Movimientos sociales y partidos políticos: aspectos de la cuestión en la democracia emergente en la Argentina». En E. JELIN (2007) (comp.): Movimientos sociales y democracia emergente/2. Buenos Aires: Centro Editor de América Latina.

Reguillo CRUZ, R. (2003): «Ciudadanías juveniles en América Latina». Última Década $\mathrm{N}^{\circ} 19$. Valparaíso: Ediciones CIDPA.

SCHUSTER, FEDERICO (2005): «Las protestas sociales y el estudio de la acción colectiva». En F. Schuster, F. NAishtat, G. NARdACChione y S. PEREYRA (comps.) Tomar la palabra. Estudios sobre protesta social y acción colectiva en la Argentina contemporánea. Buenos Aires: Prometeo.

SEMÁN, P. y P. VILA (1999): «Rock chabón e identidad juvenil en la Argentina neoliberal». En D. FILMUS: Los 90. Política, sociedad y cultura en América Latina y Argentina en fin de siglo. Buenos Aires: FLACSOEudeba.

SIDICARO, RICARDO (2013): «1983-2012: Las etapas de la transición a la democracia argentina (en claves sociológicas)». Temas y Debates, Vol. 17, N²5. Universidad Nacional de Rosario.

SVAMPA, MARISTELLA (2010): Movimientos sociales, matrices sociopolíticos y nuevos escenarios en América Latina. Working Papers 01/2010. Universität Kassel.

VÁzQUEZ, M. y P. VOMMARO (2012): «La fuerza de los jóvenes: aproximaciones a la militancia kirchnerista desde La Cámpora». En A. Natalucci y G. Pérez (2012): Vamos las bandas. Organizaciones y militancia kirchnerista. Buenos Aires: Trilce. 
VILA, PABLO (1989): «Rock nacional: crónicas de la resistencia juvenil». En E. JELIN (comp.): Los nuevos movimientos sociales. Buenos Aires: Centro Editor de América Latina.

VOMMARO, GABRIEL (2014): «Jóvenes PRO. La cara bonita de la nueva derecha». Revista Anfibia. Disponible en: www.revistaanfibia.com. 